\title{
Statistik
}

\section{Mehr Pflegebedürftige in Deutschland}

— Die Zahl Pflegebedürftiger ist in Deutschland weiter gestiegen. Nach Angaben des Statistischen Bundesamtes (Destatis) waren im Dezember 2015 2,86 Millionen Menschen pflegebedürftig, das sind $234.000(+8,9 \%)$ mehr als im Dezember 2013. 83\% der Pflegebedürftigen waren 65 Jahre und älter, mehr als ein Drittel (37\%) war mindestens 85 Jahre alt. Die Mehrheit war weiblich (64\%). Annähernd drei Viertel (2,08 Millionen) aller Pflegebedürftigen wurden zu Hause versorgt, davon 1,38 Millionen in der Regel allein durch Angehörige gepflegt. Weitere 692.000 Pflegebedürftige lebten ebenfalls in Privathaushalten, sie wurden jedoch zusammen mit ambulanten Pflegediensten oder vollständig durch diese versorgt. Gut ein Viertel (783.000 Pflegebedürftige) wurde in Pflegeheimen vollstationär betreut.

Im Vergleich mit Dezember 2013 ist die Zahl der in Heimen versorgten Pflegebedürftigen um $2,5 \%(+19.000)$ gestiegen. Deutlich höher ist die Zunahme bei der Pflege zu Hause; sie stieg im gleichen Zeitraum um 11,6 \% (+ 215.000 Pflegebedürftige). Das führen die Statistiker auch auf die Reformen der Pflegeversicherung zurück.

www.destatis.de

\section{Pflegeberufekammer}

\section{Ehrenamtliches Engagement erfolgreich}

— Vor gut einem Jahr, am 13. Januar 2016, hat der Errichtungsausschuss der Pflegeberufekammer SchleswigHolstein seine Arbeit aufgenommen. Weit über 2.000 Stunden haben die engagierten ehrenamtlichen Mitglieder seitdem investiert und damit viel erreicht. Die Voraussetzung für die Registrierung der ca. 25.000 Berufsangehörigen ist geschaffen; die ersten 400 Pflegefachpersonen haben sich bereits registriert. Über 2.000 Pflegende wurden bereits im Rahmen von Veranstaltungen über die Pflegeberufekammer informiert. „Jetzt sind die beruflich Pflegenden am Zug", konstatiert die Vorsitzende des Errichtungsausschusses Patricia Drube. „Nur durch die Registrierung können sich die zukünftigen Kammermitglieder Schleswig-Holsteins ihre Beteiligungsrechte sichern."

www.pflegeberufekammer-sh.de

\section{Hier steht eine Anzeige.}

\author{
包 Springer
}

